\title{
Interaction of the Opiate and Neuroendocrine Systems
}

Peter DeMaria, Jr, MD

Thomas Jefferson University Hospital

Follow this and additional works at: https://jdc.jefferson.edu/jeffjpsychiatry

Part of the Psychiatry Commons

Let us know how access to this document benefits you

\section{Recommended Citation}

DeMaria, Jr, MD, Peter (1985) "Interaction of the Opiate and Neuroendocrine Systems," Jefferson Journal of Psychiatry. Vol. 3 : Iss. 1 , Article 9.

DOI: https://doi.org/10.29046/JJP.003.1.005

Available at: https://jdc.jefferson.edu/jeffjpsychiatry/vol3/iss 1/9

This Article is brought to you for free and open access by the Jefferson Digital Commons. The Jefferson Digital Commons is a service of Thomas Jefferson University's Center for Teaching and Learning (CTL). The Commons is a showcase for Jefferson books and journals, peer-reviewed scholarly publications, unique historical collections from the University archives, and teaching tools. The Jefferson Digital Commons allows researchers and interested readers anywhere in the world to learn about and keep up to date with Jefferson scholarship. This article has been accepted for inclusion in Jefferson Journal of Psychiatry by an authorized administrator of the Jefferson Digital Commons. For more information, please contact: JeffersonDigitalCommons@jefferson.edu. 


\title{
INTERACTION OF THE OPIATE AND NEUROENDOCRINE SYSTEMS
}

\author{
PETER DEMARIA, JR., M.D.
}

Opiates are known to produce various physiological effects. Our understanding of these effects has been greatly increased by the discovery of the opiate receptor and the endogenous opioid peptides. Recent investigation has demonstrated that three distinct receptor subtypes exist; their function is currently being actively investigated.

Receptor theory holds that a drug's actions are the result of interactions between that drug and specific receptor molecules on the cell's surface. The location of the receptors in the body and the number of drug molecules that interact with them are important in determining the drug's effects. Variations in the drug's chemical structure will vary its affinity for the receptor. This relationship is the basis of structure activity relationships (SAR), a tool used by medicinal chemists when designing drugs. Ideally a drug will have high specificity and affinity for one type of receptor. In the field of psychopharmacology this ideal has not been achieved. Chlorpromazine, for example, interacts with cholinergic and alpha-adrenergic receptors to produce anticholinergic and orthostatic hypotensive effects as well as dopamine receptors to produce its desired antipsychotic effects. The challenge to drug designers is the synthesis of chemicals which interact with only one receptor to provide the desired effect.

Narcotic analgesics also have side effects. Morphine, a prototypical narcotic analgesic, has associated hypotensive and respiratory depressant effects which are considered disadvantageous. The narcotic antagonist naloxone has had a great impact on the practice of medicine, and research on the opiate receptor and endogenous opiates. Clinically, it is used to reverse respiratory depression in narcotic overdoses. Prior to naloxone, nalorphine could be used when a patient was brought into an emergency room with narcotic-induced respiratory depression. Nalorphine, though, has both narcotic agonist and antagonist properties. An analgesic when given alone, it antagonizes the analgesic effects of morphine when given concomitantly with morphine. The fact that one drug could have two seemingly opposite effects prompted researchers to investigate the possibility that more than one opiate receptor existed. On a tissue level, much research has been done trying to elucidate the possibility of multiple opiate receptors. Paterson, Robsen, and Kosterlitz (1) in a recent review present the biochemical data indicating the existance of three distinct opiate receptors: mu, kappa, and delta. Evidence for three distinct opiate receptors comes from the competitive displacement of tritiated ligands from receptors by unlabelled ligand. Binding assays have shown maximum binding capacities (i.e. saturability) of the

Dr. DeMaria is a first-year resident. 
different receptors by highly selective ligands. Differences in distribution patterns throughout the nervous system and the ability to selectively protect receptor subtypes from alkylation are further evidence of three distinct opiate receptors. Studying the role of each receptor is possible using receptor selective ligands. Few ligands are completely specific for one receptor and overlap exists. Medicinal chemists are attempting to synthesize more specific molecules and peptides.

Armed with these findings, researchers have been curious about the function of each receptor. For example, U 50,488, an experimental analgesic drug (2), relieves pain but not evidentally by binding, as morphine does, to mu receptors, but instead to kappa receptors. Analgesia produced by U 50,488 is reversed by naloxone, however, it lacks the morphine-type physical dependence. And while tolerance to the analgesic effect develops there is no cross tolerance to morphine. These findings with $\mathrm{U} 50,488$ raise the question of mu receptor involvement in the physical dependance seen with morphine.

The mouse vas deferens preparation is felt to be a good assay of delta receptor activity. ICI 154,129, a selective delta receptor antagonist in the mouse vas deferens preparation, does not produce the mu receptor mediated Straub tail in mice. Cowen and Gmerek (3) studied the in vivo effects of metkephamid and ICI 154,129 on charcoal meal transit time in mice. They found that ICI 154,129 reversed the meal transit time slowing produced by metkephamid. Their work provided in vivo pharmacological evidence that supports biochemical data that ICI 154,129 is a delta receptor antagonist. The lack of interaction with levorphanol, a mu receptor agonist, and naloxone, a mu receptor antagonist, in the gut is further evidence that ICI 154,129 is selective for the delta receptor.

U 50,488 and ICI 154,129 are examples of probes of the opiate receptor that can be used to better understand the function of each receptor and the role the opiate system plays in controlling homeostasis, for example, opiate's hypotensive effect. Holaday and Faden have done substantial work in this area. They administered naloxone to rats in hypovolemic (4) and endotoxic (5) shock and found it to reverse the hypotension, suggesting that the opiate receptor is involved in the pathophysiology of shock.

To better understand the mechanism involved, ICI 154,129 was used (6). Rats were injected with Escherichia coli lipopolysaccharide to induce endotoxin shock. When the mean arterial blood pressure (MABP) fell to $20-25 \mathrm{~mm}$. Hg., the animals were injected with saline or ICI 154,129 . MABP, pulse pressure, and heart rate were monitored. Changes in these parameters were reversed by ICI 154,129 but not saline. ICI 154,129 was ineffective in the rat tail flick test and the hot plate test. These findings indicate that antagonism of delta receptors would help stabilize blood pressure in shock patients. Holaday, et al., suggested that while naloxone would antagonize delta receptors in traumatic shock patients it would also antagonize mu receptor activity thereby exacerbating the patient's pain. By using a specific delta receptor antagonist, endogenous analgesia mediated by enkephalins and endorphins at the mu receptor would be unaffected, but the patient's blood pressure would be stabilized.

Curtis and Lefer (7) also attempted to dissect the receptor mechanism involved in 
the hemodynamic stabilizing effect of naloxone. Using $\mathrm{J} 7747$, a delta receptor antagonist, C 7000, a delta receptor antagonist and kappa receptor agonist, and MR 2266, a kappa receptor antagonist, they induced hemorrhagic shock in cats and monitored MABP and myocardial depressant factor (MDF) production. MDF is a biomolecule released by cells in shock and contributes to the demise of animals. Their results showed that the delta receptor antagonist $\mathrm{J} 7747$ had a significantly higher final MABP then cats treated with the delta receptor antagonist, kappa receptor agonist C 7000 , and that cats given the kappa receptor antagonist MR 2266 did not result in a significantly higher MABP than untreated hemorrhaged cats. Similar results were obtained when MDF was measured. They concluded that opiate receptors other than the kappa receptor are involved in the pathophysiology of shock and that opiate antagonist-analgesics that induce analgesia via the kappa receptor might be useful therapeutically. U 50,488, then, might be useful in trauma patients where pain and shock coexist.

Case studies in the literature have verified the effectiveness of naloxone in patients with shock. Tiengo (8) reported an eight year old admitted with septic shock and meningococcal infection in whom intensive therapy had failed to show improvement. The patient was given three doses of naloxone at 20-25 minute intervals resulting in the stabilization of blood pressure at $110 / 65 \mathrm{~mm}$. $\mathrm{Hg}$. and heart rate of $110 /$ minute. Initial values were not reported.

Wright, Phillips, and Weller (9) presented a 33-year-old female with Pseudomonas septicemia who was hypotensive (systolic, $50 \mathrm{~mm}$. Hg.), oliguric, and refractory to dopamine infusion. After naloxone was given, her blood pressure rose to $130 / 80 \mathrm{~mm}$. $\mathrm{Hg}$., her temperature returned to normal, and her urine output increased to 250 $\mathrm{ml}$./hour.

Dirksen and coworkers reported two patients (10). The first was a sixtytwo-year-old female with cardiogenic shock secondary to an extensive myocardial infarction whose blood pressure despite dobutamine infusion was $50 / 30 \mathrm{~mm}$. Hg. The patient was given naloxone which resulted in a blood pressure rise to $84 / 40 \mathrm{~mm}$. $\mathrm{Hg}$. and later to $100 / 40 \mathrm{~mm}$. $\mathrm{Hg}$. A stable clinical condition was maintained for eleven hours, after which the patient's hemodynamic status declined and she died. The second patient followed a similar course. The authors have postulated a mechanism of naloxone action in patients with shock (11). Referred to as the endorphin stress system, it ties humoral neuroendocrine factors to homeostasis. They suggest stress (e.g., severe surgical stress, hypovolemia, and various forms of shock) causes release of releasing factors and subsequently proopiocortin. Proopiocortin is the prohormone precurser which breaks down to yield adrenocorticotropic hormone (ACTH) and betaendorphin. ACTH acts on the adrenals to release cortisol and beta-endorphin at the endorphin receptor to mediate catecholamine and prostaglandin release. While the evidence for interaction between the endorphin system and the catecholamines is scant, an endorphin and opiate mediated, naloxone reversible, inhibition of $\mathrm{PGE}_{1}$-stimulated adenylate cyclase has been demonstrated (13). Catecholamines and prostaglandins have been shown to play an integral role in the control of microcirculation. 
Feedback plays an important role in this model and helps in understanding how exogenous corticosteroids may help in the therapy of patients in shock. Massive doses of steroids feed back to the hypothalamus and pituitary to suppress ACTH and beta-endorphin release. Peters, et al., reported a series of thirteen patients with prolonged hypotension (14). Eight of the patients were not receiving corticosteroids and when given naloxone showed a $45 \%$ increase in systolic blood pressure. However, in three patients receiving high doses of corticosteroids and one patient with hypoadrenocorticotropism following pituitary irradiation, naloxone failed to produce a pressor response. It was felt that the patients receiving high doses of corticosteroids or suffering hypoadrenocorticotropism would have their ACTH and beta-endorphin effectively suppressed making naloxone administration ineffective. These clinical findings support Dirksen's proposed mechanism.

Additional evidence for this neuroendocrine mechanism comes from experiments with stress-induced analgesia in animals. Exposing rats and mice to stressful stimuli such as electric foot shock, cold water swimming, centrifugal rotation, and conditioned fear produces pronounced analgesia. This analgesia is reversed by naloxone administration, which implicates the endogenous opiate system in its production. Panocka and Hartmann studied the effects of bilateral adrenalectomy (B.A.) and dexamethasone on stress-induced analgesia produced in mice by swimming (15). They separated mice into four groups: B.A. given dexamethasone on the ninth postoperative day (POD-9); B.A. given saline on POD-9; sham adrenalectomized mice given dexamethasone on POD-9; and sham adrenalectomized mice given saline on POD-9. Analgesia was tested using hind paw flick as the endpoint in the mouse hot plate test. From this data the authors conclude that pituitary opiates are involved in stress-induced analgesia. Their results support Dirksen's mechanism. Both adrenalectomized groups showed an accentuation of post-stress analgesia. Regardless of the surgical procedure performed, dexamethasone attenuated post-stress analgesia. Once feedback to the pituitary is removed (e.g., adrenalectomy) there is a compensatory increase in ACTH and therefore beta-endorphin. Likewise, with increased feedback (e.g., dexamethasone) to the pituitary, ACTH and beta-endorphin are suppressed. Analgesia is mediated by the level of beta-endorphin at the receptor.

Mousa, Miller, and Couri examined the effect of dexamethasone and naloxone on cold water swimming-induced analgesia in rats (16). In this study, one group of rats was pre-treated with dexamethasone for three days. Another group of rats was given naloxone thirty minutes prior to the stressor. A third control group of rats received an equivolume dose of saline. Pain sensitivity was tested by both the hot plate and tail flick tests. Dexamethasone significantly increased the baseline prestressor pain threshold in the hot plate, but not the tail flick tests. The authors felt that the discrepancies between the tests might be explained by the discrepancies between detectable pain thresholds or involvement of different pain pathways in the two methods. They noted a similar phenomenon had been reported with DMSO, neurotensin, and enkephalins. Pretreatment with dexamethasone produced suppression of stressor-induced analgesia in both tests. Naloxone administered to control rats partially antagonized the stress-induced 
analgesia. The researchers concluded that dexamethasone may act through an indirect mechanism to inhibit the stress-induced elevation of beta-endorphin by acting directly on the pain-inhibiting system or via the hormones involved in temperature regulation.

Data presented by different researchers indicates a clear relationship between opioid and neuroendocrine systems that is probably best summarized by the model proposed by Dirksen and coworkers. A better understanding of pathophysiological mechanisms will no doubt emerge from further investigation. The elucidation of the endorphin stress system's function in patients with shock is an example.

Research presented in this paper demonstrates a new tie between the endogenous opiate system and the endocrine system. This tie, in the form of proopiocortin, opens avenues to a better understanding of stress whether induced by pain, shock, or other factor. Perhaps one field that will greatly benefit is psychiatry. Psychiatrists are familiar with the number of ways humans respond to stress (e.g. depression, anxiety, chronic pain). The dexamethasone suppression test (DST) currently implicates a neuroendocrine mechanism in patients suffering from depression. Depression is frequently implicated as a cause of chronic pain. Psychiatrists believe anxiety is a response to an internal stressor. Both fear, a response to a real external stressor, and anxiety produce the same symptoms. What interactions with opiate and neuroendocrine systems may be present in anxiety? And what is the role of the opiate and neuroendocrine systems in chronic pain? Recent research has raised speculation. Römer and coworkers reported the synthesis of an opioid benzodiazepine $(17,18)$. Benzodiazepines are widely used in the treatment of anxiety. As with opiates, a receptor that specifically binds benzodiazepines has been identified in the brain. There has also been good correlation between receptor binding affinity and therapeutic effect. The molecule synthesized by Römer and coworkers, while chemically a benzodiazepine, shows no affinity for the benzodiazepine receptor; but rather acts selectively on the opiate kappa receptor, acting effectively as an analgesic and reversed by naloxone. The research is still preliminary, but it raises questions about interactions between opiate and benzodiazepine systems and their role in pain, stress, and anxiety.

\section{REFERENCES}

1. Patersen SJ, Robson LE, Kosterlitz NW: Classification of opiate receptors. Brit Med Bull 39: 31,1983

2. VonVoigtlander PF, Collins RJ, Lewis RA, Neff GL: U 50,488 (trans-3,4-dichloroN-methyl-N-(2-(1-pyrrolidnyl) cyclohexyl)benzeacetamide): prototype for a new class of opioid analgesics. Pharmacologist 23: 112, 1981

3. Cowan A, Gmerek DE: In vivo studies with ICI 154,129, a putative delta receptor antagonist. Lf Sci 31: 2213, 1982

4. Holaday JW, Faden AI: Naloxone reversal of endotoxin hypotension suggests role of endorphins in shock. Nat 275: 450, 1978

5. Faden AI, Holaday JW: Opiate antagonists: a role in the treatment of hypovolemic shock. Sci 205: 317, 1979

6. Holaday JW, Ruvio BA, Robles LE, Johnson CE, D'Amato RJ: M 154,129, a putative delta 
antagonist, reverses endotoxic shock without altering morphine analgesia. Lf Sci 31: 2209, 1982

7. Curtis M, Lefer A: Action of opiate antagonists with selective receptor interactions in hemorrhagic shock. Circ Shock 10: 131, 1983

8. Tiengo M: Naloxone in reversible shock. Lanc 2: 1360, 1980

9. Wright D, Phillips M, Weller M: Letter to the editor. Lanc 2: 1361, 1980

10. Dirksen R, et al: Naloxone in shock. Lanc 2: 1360, 1980

11. Kirksen R, Wood GJ, Nijhuis GMMM: Mechanism of naloxone therapy in the treatment of shock, a hypothesis. Lanc 1: 607, 1981

12. Iverson L, Iverson S, Snyder S: Neuropeptides, in Handbook of Psychopharmacology, Volume 16. New York, Plenum, 1983

13. Klee WA, Lampert A, Nirenberg M: Dual regulation of adenylate cyclase by endogenous opiate peptides, in Opiates and Endogenous Opioid Peptides. Elseview, North Holland Biomedical Press, 1976

14. Peters WP, Johnson MW, Friedman PA, Mitch WE: Pressor effects of naloxone in septic shock. Lanc 1: 529, 1981

15. Panocka P, Hartmann G: Enhancement of stress-induced analgesia in adrenalectomized mice, its reversal by dexamethasone. Pharmacol Biochem Behav 16: 403, 1982

16. Mousa S, Miller CH, Couri D: Dexamethasone and stress-induced analgesia. Psychopharm 79: 199, 1983

17. Romer D, et al: Unexpected opioid activity in a known class of drugs. Lf Sci 31: 1217, 1982

18. Romer D, et al: An opioid benzodiazepine. Nat 298: 757, 1982 